\title{
A novel mechanism for HIV1-mediated bystander CD4 + T-cell death: neighboring dying cells drive the capacity of HIV1 to kill noncycling primary CD4 + T cells
}

\author{
JD Lelièvre ${ }^{\star, 1}, \mathrm{~F}$ Mammano ${ }^{2}$, D Arnoult ${ }^{1}, \mathrm{~F}$ Petit $^{1}$, A Grodet $^{3}$, \\ $\mathrm{J}$ Estaquier ${ }^{1}$ and $\mathrm{JC}$ Ameisen $^{\star, 1}$ \\ ${ }^{1}$ EMI-U 9922 INSERM/Université Paris 7, IFR02, AP-HP, Faculté de Médecine \\ Xavier Bichat, 16 rue Henri Huchard, 75018 Paris, France; \\ 2 INSERM U 552, IFR02, IMEA, Hôpital Bichat-Claude Bernard, Paris; \\ ${ }^{3}$ INSERM U 327, IFR02, Faculté de Médecine Xavier Bichat, 16 rue Henri \\ Huchard, 75018 Paris, France \\ * Corresponding authors: JC Ameisen, EMI-U 9922 INSERM/Université Paris 7 \\ IFR02, AP-HP, Faculté de Médecine Xavier Bichat, 16 rue Henri Huchard, \\ 75018 Paris, France. Tel: + 3314485 61 50; Fax: + 331448561 49; \\ E-mail: ameisen@wanadoo.fr, or JD Lelièvre, E-mail: lelievre@im3.inserm.fr
}

Received 11.2.04; accepted 26.2.04; published online 30.4.04 Edited by G Melino

\begin{abstract}
CD4 + T-cell death is a crucial feature of AIDS pathogenesis but the mechanisms involved remain unclear. Here, we present in vitro findings that identify a novel process of HIV1 mediated killing of bystander CD4 $+\mathrm{T}$ cells, which does not require productive infection of these cells but depends on the presence of neighboring dying cells. X4-tropic HIV1 strains, which use CD4 and CXCR4 as receptors for cell entry, caused death of unstimulated noncycling primary CD4 $+T$ cells only if the viruses were produced by dying, productively infected $T$ cells, but not by living, chronically infected $T$ cells or by living HIV1-transfected HeLa cells. Inducing cell death in HIV1transfected HeLa cells was sufficient to obtain viruses that caused CD4 + T-cell death. The addition of supernatants from dying control cells, including primary $T$ cells, allowed viruses produced by living HIV1-transfected cells to cause CD4 + Tcell death. CD4 + T-cell killing required HIV1 fusion and/or entry into these cells, but neither HIV1 envelope-mediated CD4 or CXCR4 signaling nor the presence of the HIV1 Nef protein in the viral particles. Supernatants from dying control cells contained CD95 ligand (CD95L), and antibody-mediated neutralization of CD95L prevented these supernatants from complementing HIV1 in inducing CD4 + T-cell death. Our in vitro findings suggest that the very extent of cell death induced in vivo during HIV1 infection by either virus cytopathic effects or immune activation may by itself provide an amplification loop in AIDS pathogenesis. More generally, they provide a paradigm for pathogen-mediated killing processes in which the extent of cell death occurring in the microenvironment might drive the capacity of the pathogen to induce further cell death. Cell Death and Differentiation (2004) 11, 1017-1027.

doi:10.1038/sj.cdd. 4401441

Published online 30 April 2004
\end{abstract}

Keywords: AIDS; CD4; CD4 + T cells; CD95 ligand; cell death; CXCR4; Env; HIV; Nef; pathogenesis

Abbreviations: CD95L, CD95 (Fas) ligand; $\Delta \Psi \mathrm{m}$, mitochondrial transmembrane potential; Env, envelope protein; GFP, green fluorescent protein; HIV, human immunodeficiency virus; mAb, monoclonal antibody; MuLV, murine leukemia virus; NL4-3/ env, vector encoding NL4-3 deleted in its env gene; NL4-3/nef, vector encoding NL4-3 deficient in its nef gene; NL4-3/MuLV env, NL4-3 viruses pseudotyped with the amphotropic MuLV env gene; sCD4, human soluble recombinant CD4; SIV, simian immunodeficiency virus; srCD95L, soluble recombinant FLAGtagged CD95L; TNF, tumor necrosis factor

\section{Introduction}

The induction of progressive CD4 + T-cell depletion, leading to immune dysfunction, is a hallmark of HIV1 infection. The mechanisms by which HIV1 induces CD4 + T-cell death, however, remain a critical unresolved issue of AIDS pathogenesis. $^{1-4}$ At least three major, nonmutually exclusive mechanisms have been proposed. The first one is the killing of productively infected CD4 + T cells, caused either by direct viral cytopathic effects or by antiviral cytotoxic CD8 + T lymphocytes. ${ }^{5-7}$ The second one is the viral-mediated killing of bystander uninfected CD4 + T cells, induced by the binding or entry of viral proteins that are released by infected cells, or that are present on, or inside, the viral particles..$^{1,2,8-10}$ The third proposed mechanism is excessive, ongoing immune activation caused by a high, persistent viral antigen load and leading to the activation-induced death of various uninfected immune cells, including CD4 + T cells. ${ }^{1,2,4,8,9}$

Evidence for the involvement of indirect mechanisms of CD4 + T-cell killing has been provided by the identification in vivo $^{11-16}$ and ex vivo ${ }^{17-19}$ of increased number of dying, uninfected immune cells, including CD4 $+\mathrm{T}$ cells, both in HIV1-infected persons and in non-human primate models of pathogenic simian immunodeficiency virus (SIV) infection, that are closely related to HIV. An important question is whether HIV1 may only cause death in activated, cycling CD4 + T cells, or also in unstimulated noncycling CD4 + T cells, which represent at any given time point the vast majority of the CD4 + T cells in HIV1-infected persons. ${ }^{3}$ Because most of the viral particles produced during HIV1 infection are replication-defective, ${ }^{6}$ but can still bind to-, and enter into$\mathrm{CD} 4+\mathrm{T}$ cells, viral proteins present at the surface or inside the viral particles have been proposed as candidates for the killing of noncycling CD4 $+\mathrm{T}$ cells in the absence of productive infection of these cells. In vitro findings have suggested that among such viral proteins, the HIV1 surface 
envelope (Env) constitutes a major potential candidate for the HIV1-mediated killing of CD4 + T cells in the absence of productive infection, ${ }^{16,20-26}$ through death signaling caused by engagement of either its cell-surface receptor, CD4 ${ }^{27-29}$ or, for the Env of X4-tropic HIV1 strains, of its CXCR4 coreceptor. $^{25,26,30,31}$ Incubation of noncycling, primary CD4 + T cells with X4-tropic HIV1 viral particles has been previously reported to cause CD4 + T-cell death, after a delay of 3-4 days. ${ }^{32,33}$

The aims of our study were first to confirm this latter finding, and then to investigate the mechanisms involved. Here we show that the presence of dying cells in the HIV1-producing cell culture - which is the source of the viral particles - is a crucial, previously unsuspected cofactor required for the HIV1 particles to cause bystander CD4 + T-cell killing. In the presence of cellular components released by dying cells, CD4 + T-cell killing required HIV1 entry into these cells, but did not result from Env-mediated CD4 or CXCR4 signaling, since pseudotyped HIV1 particles expressing the murine leukemia virus (MuLV) amphotropic Env instead of the HIV1 Env showed similar killing activity. Together, our in vitro findings imply that the extent of cell death occurring in vivo during HIV1 infection, whatever its causal mechanism and the nature of the dying cells, may by itself allow, in the presence of a sufficient amount of HIV1 particles, the induction of an additional, pathogenic mechanism causing further bystander CD4 + T-cell killing. These findings may have important implications for our understanding of AIDS pathogenesis.

\section{Results}

\section{X4-tropic HIV1 strains induce death of unstimulated primary CD4 $+\mathrm{T}$ cells}

We first used the well-characterized X4-tropic HIV1 laboratory-adapted strain LAI. CD4 + T cells from the peripheral blood of healthy HIV-seronegative controls were purified by negative selection ( $>95 \%$ pure) and incubated with increas-

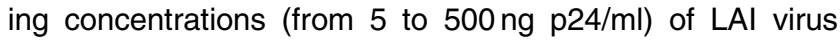
collected from productively infected CEM T-cell cultures at the peak of viral production (around 8 days after infection). In the absence of additional stimulus, HIV1 induced a dosedependent process of CD4 + T-cell death, which began to be detectable after 2 days and was maximal after 4 days (data not shown). While supernatants from uninfected control-CEM cultures caused less than 15\% CD4 + T-cell loss after 4 days, HIV1 (at a concentration of $500 \mathrm{ng} \mathrm{p} 24 / \mathrm{ml}$ ) led to the loss of more than $45 \%$ CD4 + T cells, thus causing more than $30 \%$ CD4 + T-cell death in excess of the control (Figure 1a). Quiescent CD4 + T lymphocytes are not permissive to HIV1 infection in the absence of additional stimuli. ${ }^{34,35}$ PCR analysis indicated the absence of detectable HIV1 proviral integration in the purified primary CD4 + T cells after 4 days incubation with the virus (data not shown), and p24 ELISA analysis indicated the absence of detectable virus production (Figure 1b), in contrast with the expected significant production induced after 4 days by PHA/IL2 stimulation (Figure 1b). Pretreatment of CD4 $+\mathrm{T}$ cells with an effective combination of the reverse transcriptase inhibitors AZT $(1 \mu \mathrm{M})$ and ddl $(1 \mu \mathrm{M})$ did not prevent HIV1-induced CD4 + T-cell death
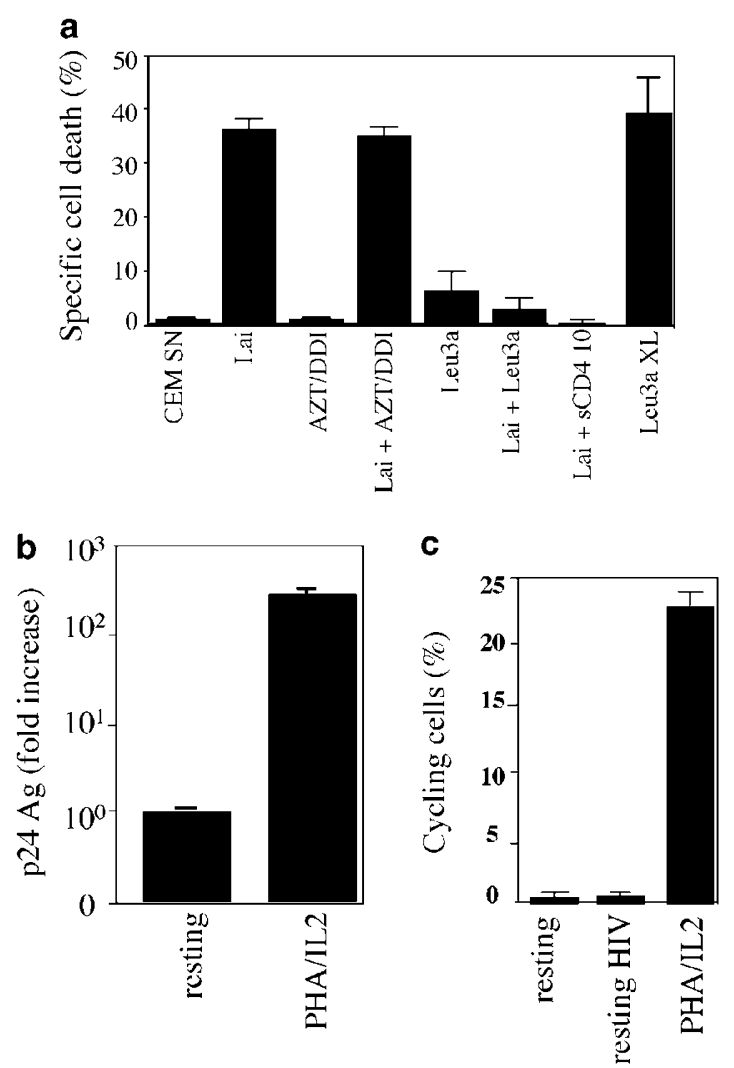

Figure 1 The X4-tropic HIV1 strain LAI induces death of noncycling purified primary CD4 $+\mathrm{T}$ cells in the absence of productive infection. (a) Purified unstimulated CD4 + T cells $\left(10^{6} / \mathrm{ml}\right)$ were incubated with either supernatants from uninfected CEM cell culture (CEM SN) (lane 1), the HIV1 X4-tropic LAI virus $(500 \mathrm{ng} \mathrm{p} 24 / \mathrm{ml})$ (collected from productively infected CEM cell culture supernatants at the peak of viral production (Lai) (lane 2), a combination of AZT and ddl ( $1 \mu \mathrm{M}$ each) in the absence (lane 3 ) or presence (lane 4$)$ of the Lai virus $(500 \mathrm{ng} / \mathrm{ml})$, the CD4-specific mAb Leu3a $(10 \mu \mathrm{g} / \mathrm{ml}$ in solution) in the absence (lane 5) or presence (lane 6) of the same source of Lai virus $(500 \mathrm{ng} / \mathrm{ml}), 500 \mathrm{ng}$ of Lai that had been preincubated for $1 \mathrm{~h}$ with soluble recombinant CD4 $(10 \mu \mathrm{g} /$ $\mathrm{ml}$ ) (lane 7), or plate-immobilized CD4-specific (Leu3a XL) mAb $(10 \mu \mathrm{g} / \mathrm{ml})$ in the absence of virus (lane 8 ). (b) Purified unstimulated primary CD4 $+\mathrm{T}$ cells were incubated with the HIV1 X4-tropic Lai virus (500 ng p24/ml) in the absence (Lai) or presence (Lai + PHA/IL2) of $1 \mu \mathrm{g} / \mathrm{ml} \mathrm{PHA-P} \mathrm{(Sigma)} \mathrm{and} 100 \mathrm{UI} / \mathrm{ml} \mathrm{IL2}$, and HIV p24 antigen production was measured after a 5-day culture. (c) Purified unstimulated primary CD4 $+\mathrm{T}$ cells were incubated with supernatants from uninfected CEM cell cultures (CEM SN) (lane 1), or with the HIV1 X4-tropic Lai virus (500 ng p24/ml) in the absence (Lai) (lane 2) or presence (Lai + PHA/IL2) of $1 \mu \mathrm{g} / \mathrm{ml} \mathrm{PHA}-\mathrm{P}$ (Sigma) and $100 \mathrm{UI} / \mathrm{ml}$ IL2 (lane 3). Percentages of cycling cells (in the $\mathrm{S}$ or G2/M phase) were assessed after a 4-day culture by flow cytometry analysis using propidium iodide staining. Percentages of specific cell death after a 4-day culture shown in (a) were calculated as indicated in Materials and methods. Background cell death levels (corresponding to $0 \%$ specific cell death) were less than $15 \%$. All results shown in $(\mathbf{a}-\mathbf{c})$ are means \pm S.D. of four independent experiments each performed in triplicate

(Figure 1a), confirming that HIV1 proviral integration and expression were not required for the induction of cell death. Cell cycle analysis using either tritiated thymidine incorporation (data not shown) or flow cytometry analysis of propidium iodide staining (Figure 1c) indicated that incubation with HIV1 did not cause entry in cell cycle, confirming that the viruses induced death of resting CD4 + T cells. We then explored the effect on CD4 + T-cell death of two treatments that prevent the HIV1 envelope protein (Env) from binding to its CD4 
cell-surface receptor, the preincubation of the CD4 $+\mathrm{T}$ cells with the CD4-specific Leu3a antibody, ${ }^{36,37}$ or the preincubation of the viruses with a high concentration $(10 \mu \mathrm{g} / \mathrm{ml})$ of human soluble recombinant CD4 (sCD4). ${ }^{38}$ Both treatments prevented the capacity of HIV1 to induce CD4 + T-cell death (Figure 1a), indicating that an interaction of the HIV1 Env with the CD4 cell-surface receptors was one of the events required for the induction of CD4 + T-cell death. While the Leu3a antibody added in solution did not by itself affect CD4 + T-cell survival (Figure 1a), CD4 receptor engagement by plateimmobilized Leu3a induced death in the same proportion of CD4 + T cells as HIV1 (Figure 1a), consistent with previous reports, ${ }^{27-30}$ and with the suggestion that HIV1 Env-mediated engagement of its CD4 cell-surface receptor may by itself cause CD4 + T-cell death. ${ }^{20-22,24}$ However, because CD4specific antibodies may induce different cell signaling than HIV1 viral particles, we investigated whether HIV1-mediated CD4 + T-cell death might rather be due to post-CD4-binding events. Preincubation of X4-tropic HIV1 with high concentrations of sCD4 blocks Env binding to both CD4 and CXCR4 cell-surface receptors, but preincubation with suboptimal sCD4 concentrations induces Env conformational changes that allow it to directly engage $\mathrm{CXCR} 4,{ }^{39,40}$ thus bypassing the prior requirements to bind the CD4 cell-surface receptor. A dose-response experiment indicated that while preincubation of LAl viruses with $10 \mu \mathrm{g} / \mathrm{ml} \mathrm{sCD4}$ prevented CD4 + T-cell death, preincubation with $0.1 \mu \mathrm{g} / \mathrm{ml} \mathrm{sCD} 4$ had no inhibitory effect (Figure 2a). In contrast with untreated viruses, viruses preincubated with $0.1 \mu \mathrm{g} / \mathrm{ml} \mathrm{sCD} 4$ induced CD4 + T-cell death even when the cells were pretreated with the Leu3a antibody added in solution (Figure 2a), which prevents Env binding to the CD4 cell-surface receptor, ${ }^{36,37}$ and HIV1mediated CD4+ T-cell death in the absence of virus preincubation with $0.1 \mu \mathrm{g} / \mathrm{ml} \mathrm{sCD} 4$ (Figure 1a). This suggested, as previously proposed, ${ }^{25,26}$ that HIV1-mediated cell death might be due to post-CD4 binding events, such as HIV1 env engagement of its CXCR4 receptor. Consistent with a previous report, ${ }^{30}$ plate-immobilized CXCR4-specific antibodies also induced CD4 + T-cell death (Figure 2b), although to a lesser extent than the virus. However, because the CXCR4specific antibodies caused CD4 + T-cell death both when plate-immobilized or when added in solution (data not shown), we could not use these antibodies to assess whether blocking HIV1 Env interactions with CXCR4 might prevent or reduce HIV1-mediated CD4 + T-cell death.

Thus, to further investigate the potential role of the HIV1 coreceptors, we compared the effect on CD4 + T-cell survival of two other X4-tropic HIV1 strains, NL4-3 and R9, that also use CXCR4 as a coreceptor, and of two R5-tropic HIV1 strains, BaL and ADA, that use the CCR5 chemokine receptor as a coreceptor. All viruses were collected at the peak of viral production from productively infected, CCR5-transfected CEM cells, which are permissive for infection and replication of both X4-tropic and R5-tropic HIV1 strains. The two additional X4-tropic strains induced CD4 + T-cell death as LAI, while the two R5 strains did not affect the CD4 + T-cell survival (Figure 2b). Also, in contrast with the antibodymediated engagement of CXCR4, that of CCR5 did not induce CD4 + T-cell death (Figure $2 b$ ). Flow cytometry analysis of cell-surface expression of the CXCR4 and CCR5 receptors by
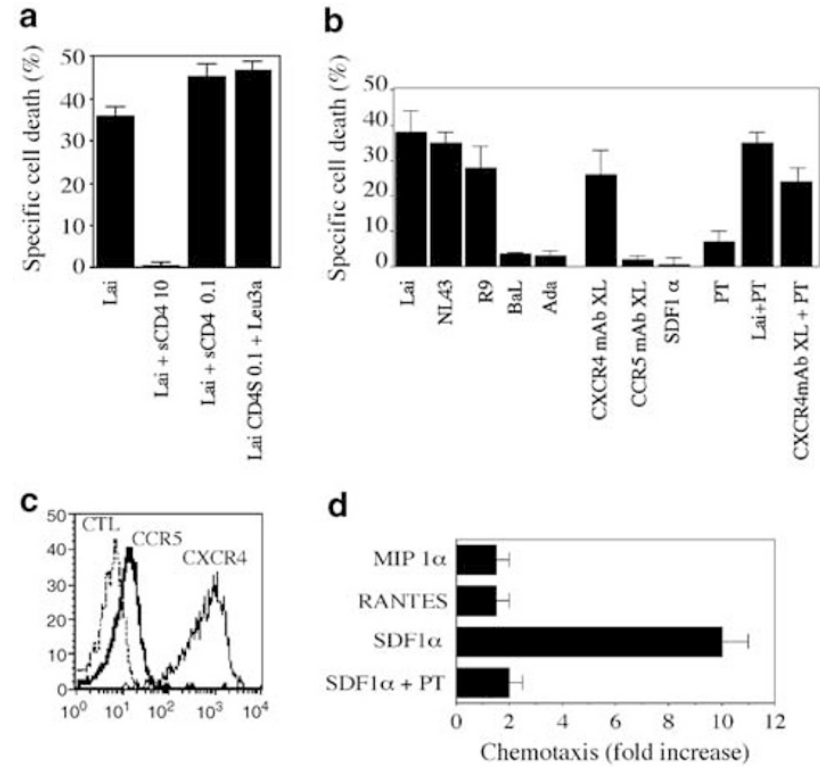

Figure 2 X4-tropic, but not R5-tropic, HIV1 cause death of noncycling purified primary CD4 + T cells. (a) Purified unstimulated primary CD4 + T cells $\left(10^{6} / \mathrm{ml}\right)$ were incubated with the X4-tropic LAl viruses (Lai) $(500 \mathrm{ng} \mathrm{p} 24 / \mathrm{ml}$, as in Figure 1) or with Lai viruses $(500 \mathrm{ng} \mathrm{p} 24 / \mathrm{ml})$ that had been preincubated for $1 \mathrm{~h}$ with soluble recombinant CD4 (10 or $0.1 \mu \mathrm{g} / \mathrm{ml}$, respectively) (Lai + SCD4 10 or $\mathrm{Lai}+\mathrm{SCD} 40.1)$ in the absence or presence of preincubation of the CD4 + T cells with the CD4-specific mAb Leu3a (10 $\mu \mathrm{g} / \mathrm{ml}$ in solution) for $1 \mathrm{~h}$ (Lai + sCD4 $0.1+$ Leu3a). (b) Purified unstimulated primary CD4 + T cells were incubated with $500 \mathrm{ng} \mathrm{p24/ml} \mathrm{of} \mathrm{either} \mathrm{HIV1} \mathrm{X4-tropic} \mathrm{viruses} \mathrm{(Lai,} \mathrm{NL4-3,} \mathrm{or} \mathrm{R9)} \mathrm{or} \mathrm{HIV1}$ R5-tropic viruses (BaL or Ada) collected from productively infected CEM-HIV1 LTR-GFP-CCR5 ${ }^{+}$cells (see Materials and methods) at the peak of viral production; purified unstimulated CD4 $+\mathrm{T}$ cells were incubated in the absence of virus with plate-immobilized CXCR4-specific (CXCR4 mAb XL) or CCR5specific (CCR5 mAb XL) mAb (10 $\mu \mathrm{g} / \mathrm{ml})$, or with the SDF1 chemokine (100 nM). Purified CD4 + T cells were incubated with the G-protein inhibitor Bordetella pertussis toxin $(10 \mathrm{ng} / \mathrm{ml})$ in the absence (PT) or presence of either $500 \mathrm{ng} \mathrm{p} 24 / \mathrm{ml}$ Lai viruses (Lai $+\mathrm{PT})$ or of $10 \mu \mathrm{g}$ plate-immobilized CXCR4-specific mAb (CXCR4 mAb XL + PT). (c) Cell-surface expression of the CXCR4 and CCR5 chemokine receptors was assessed by flow cytometry analysis on purified unstimulated primary CD4 $+\mathrm{T}$ cells after the purification procedure. (d) Quantitative chemotaxis migration assays. Purified unstimulated primary CD4 + $T$ cells were added, after the purification procedure, to the top chamber of a Transwell chamber while either medium alone or the SDF1, MIP1 $\alpha$ or RANTES chemokines $(25 \mathrm{nM})$ or both the SDF1 chemokine and the Bordetella pertussis toxin (SDF $1 \alpha+\mathrm{PT}$ ) were added to the lower chamber. After $2 \mathrm{~h}$ at $37^{\circ} \mathrm{C}$, cells that had migrated to the lower chamber were collected and counted using flow cytometry analysis. Results are expressed as fold increase in migration induced by each chemokine over medium alone. Percentages of specific cell death after a 4-day culture shown in $(\mathbf{a}, \mathbf{b})$ were calculated as indicated in Materials and methods. All results shown in $(\mathbf{a}, \mathbf{b}, \mathbf{d})$ are means \pm S.D. of four independent experiments each performed in triplicate

purified primary CD4 + T cells, as well as functional analysis of the chemotactic response of these CD4 $+\mathrm{T}$ cells to the physiological chemokine ligands of these receptors provided a simple explanation for these findings. Indeed, CXCR4 expression on purified primary CD4 + T cells was high, while CCR5 expression was very low (Figure 2c), as previously reported, ${ }^{41}$ and $\mathrm{CD} 4+\mathrm{T}$ cells showed a chemotactic response to the SDF1 agonist of CXCR4, but no significant chemotactic response to the MIP1 and RANTES agonists of CCR5 (Figure 2d). In contrast with the X4-tropic HIV1 strains and with the CXCR4-specific antibody, the SDF1 chemokine did not induce CD4 + T-cell death (Figure 2b). The CXCR4- 
mediated chemotactic response to SDF1 depends on $\mathrm{Gi}$ protein signaling, which is inhibited by pertussis toxin. ${ }^{42}$ While pertussis toxin blocked the chemotactic response of CD4 + T cells to SDF1 (Figure 2d), it did not prevent Lai (or CXCR4specific antibody) from inducing CD4 + T-cell death (Figure $2 \mathrm{~b}$ ). Thus, a possible interpretation for our findings was that X4-tropic HIV1 might cause CD4 + T-cell death as a consequence of Env binding to CXCR4, through a CXCR4 signaling pathway differing from that involved in its physiological response to SDF1, as previously proposed. ${ }^{26}$ Another possibility, however, was that X4-tropic HIV1 did not cause CD4 + T-cell death through either CD4 or CXCR4 signaling, but rather that killing was a postbinding consequence of viral entry into the cells. To discriminate between these possibilities, we decided to investigate the effect of chimeric X4-tropic NL4-3 viruses obtained by pseudotyping the HIV env with the amphotropic env of another retrovirus, the MuLV, that does not require interaction with CD4 or any chemokine receptor to enter into cells. ${ }^{43,44}$ Because we produced pseudotyped NL43 viruses by transfecting HeLa cells, we first explored the effect in our model of native NL4-3 viruses collected from transfected HeLa cells.

Figure 3 The X4-tropic HIV1 NL4-3 requires cellular cofactors released by dying cells in order to induce death of unstimulated purified primary CD4 + T cells (a) Purified unstimulated primary CD4 $+\mathrm{T}$ cells $\left(10^{6} / \mathrm{ml}\right)$ were incubated with NL4-3 viruses (500 ng p24/ml) collected from either NL4-3-infected CEMHIV1 LTR-GFP-CCR5 ${ }^{+}$cells (see Materials and methods) at the peak of viral production (Infection + ) or from NL4-3-transfected HeLa cells, $48 \mathrm{~h}$ after transfection (Transfection + ). When so indicated (Purification + ), viruses were further purified and concentrated by centrifugation of supernatants through 0.45 $0.1 \mu \mathrm{m}$ pore size filters retaining the $100-450 \mathrm{~nm}$ supernatant fraction (see Materials and methods). Results are means \pm S.D. of three independent experiments each performed in triplicate. (b) CEM-HIV1 LTR-GFP-CCR5 ${ }^{+}$cells were infected with HIV NL4-3 and both the percentages of productively infected CEM cells expressing GFP (GFP expression \%) and the percentages of dying CEM cells (CEM cell death \%) were monitored at days (D) 4, 8, or 50 postinfection by flow cytometry analysis of GFP expression and both annexin $\mathrm{V}$ PE staining and DiOC6 $(\Delta \Psi \mathrm{m})$ labeling, respectively. Results are means \pm S.D. of three independent experiments each performed in triplicate. (c) NL4-3 viruses were collected from NL4-3-infected CEM-HIV1 LTR-GFP-CCR5 ${ }^{+}$cells at days (D) 4, 8, or 50 postinfection, and purified as described in (a), and incubated (500 ng p24/ml) with purified unstimulated primary CD4 + T cells $\left(10^{6} / \mathrm{ml}\right)$ for 4 days. Results are means \pm s.d. of three independent experiments each performed in triplicate. (d) HeLa cells were transfected with either NL4-3 (HIV transfection +) or with a control plasmid (HIV transfection-) and supernatants were purified as in (a). In some cultures, the transfected HeLa cells were UV irradiated for $5 \mathrm{~min} 33 \mathrm{~h}$ after transfection, and supernatants were purified as above $15 \mathrm{~h}$ after ( $48 \mathrm{~h}$ after transfection) (UV irradiation + ). Purified unstimulated primary CD4 + T cells $\left(10^{6} / \mathrm{ml}\right)$ were incubated with viruses $(500 \mathrm{ng} \mathrm{p} 24 / \mathrm{ml})$ purified from either living (UV irradiation-) or dying UV-irradiated (UV irradiation +) NL4-3-transfected HeLa cells, or with an equivalent volume of purified supernatant (100-450 nM fraction) from UV-irradiated control-transfected HeLa cells (HIV transfection-). Results are means +S.D. of one representative experiment out of three performed in triplicate. (e) Purified unstimulated primary $\mathrm{CD} 4+\mathrm{T}$ cells $\left(10^{6} / \mathrm{ml}\right)$ were incubated with either viruses

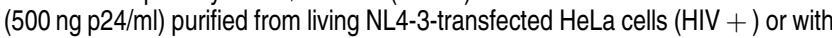
supernatants from living control-transfected HeLa cells (HIV-), in the presence of an equal volume of purified supernatants $(100-450 \mathrm{~nm}$ fraction) (SN) from either living control-transfected HeLa cells (Living HeLa), from dying UVirradiated control-transfected HeLa cells (HeLa UV), from dying, serum-deprived control-transfected HeLa cells (HeLa serum deprived), or from dying, serumdeprived PBMC (PBMC serum deprived). Results are means + S.D. of one representative experiment out of three performed in triplicate. Percentages of specific cell death after a 4-day culture shown in $(\mathbf{a}, \mathbf{c}-\mathbf{e})$ were calculated as indicated in Materials and methods

\section{X4-tropic HIV1 NL4-3 requires cellular cofactors released by dying cells in order to kill unstimulated primary CD4 $+\mathrm{T}$ cells}

We incubated primary CD4 + T cells with viruses (500 ng p24/ $\mathrm{ml}$ ) purified and concentrated from supernatants of HeLa cells $48 \mathrm{~h}$ after transfection with a vector encoding the native NL43. Virus purification and concentration was performed by centrifugation through $0.45-0.1 \mu \mathrm{m}$ pore size filters, thus retaining the $100-450 \mathrm{~nm}$ fractions. As a negative control, we used supernatants purified and concentrated by the same procedure from HeLa cells transfected with a control vector ( $p$ Blue Script), and as a positive control we used the same concentration ( $500 \mathrm{ng} \mathrm{p} 24 / \mathrm{ml}$ ) of NL4-3 viruses collected from supernatants of productively infected CEM cell cultures, as in the experiments described above (Figure $2 b$ ). Surprisingly, NL4-3 purified from transfected HeLa cells did not affect CD4 + T-cell survival (Figure 3a). These NL4-3 viruses were replication-competent in CEM cells (data not shown), and acquired the capacity to induce death in primary CD4 $+\mathrm{T}$ cells once they were purified after having been allowed to replicate in CEM cells (Figure 3a). At this stage, we decided to explore the basis for this striking difference between these NL4-3 viruses (Figure 3a), which seemed to depend on their cellular origin. Because HeLa cells, in contrast to CEM T cells, are not permissive for HIV1 entry and infection, we reasoned that one possible explanation for this difference might be due to the fact that HIV1 replication in permissive cells leads to HIV1-mediated cytopathic effects, the peak of cell death occurring at the period of peak viral production, the very time

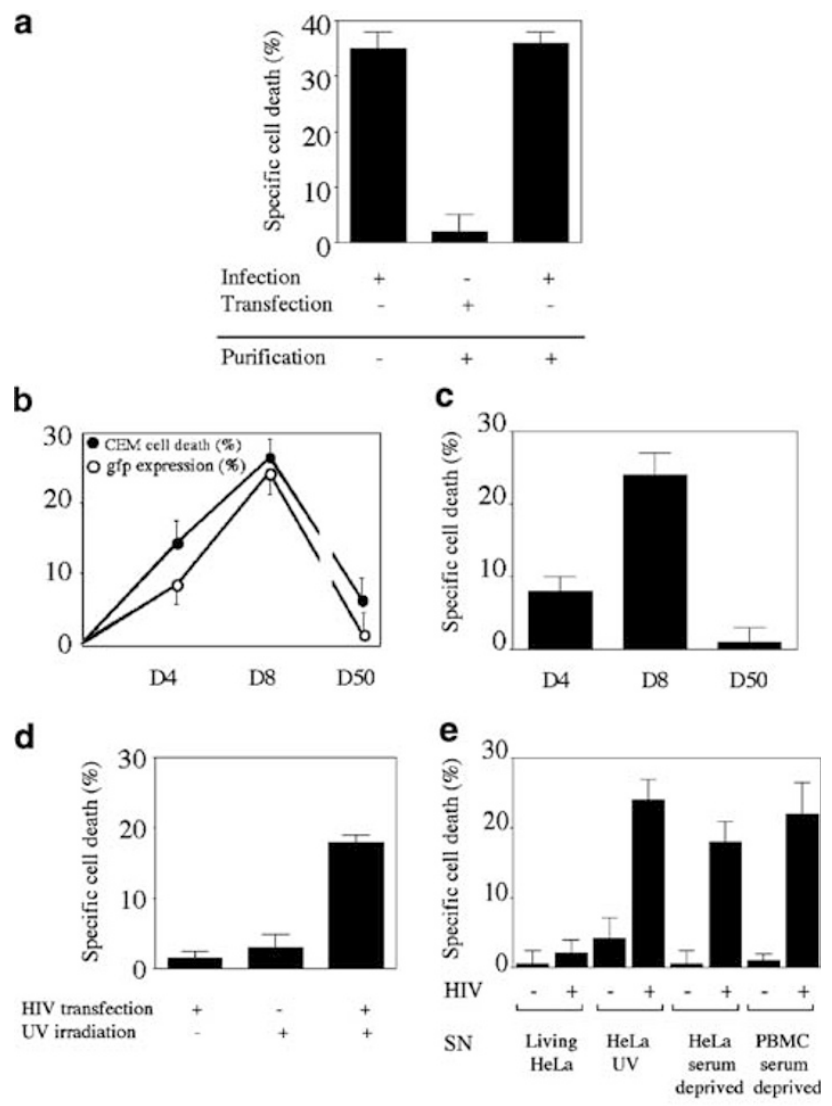


point at which we collected the virus from productively infected CEM cells in all above-described experiments. In contrast, HeLa cells, which are not permissive for HIV1 entry and infection, had no viability loss $48 \mathrm{~h}$ after transfection with the NL4-3 vector, the time point at which we collected the viral particles (data not shown). In productively infected CEM cells, both viral replication and cell death increased from day 4 to day 8 during the acute period of infection, and were very low in chronically infected cells at day 50 (Figure 3b). When we incubated unstimulated primary CD4 $+\mathrm{T}$ cells with equal concentrations (500 ng $\mathrm{p} 24 / \mathrm{ml}$ ) of NL4-3 viruses that had been purified from the CEM cell cultures at days 4,8 , or 50 after infection, the extent of CD4 + T-cell death induced was highest for viruses collected at day 8 (the peak of cytopathic cell death) and lowest for viruses collected at day 50 (Figure 3c). We then decided to explore directly the hypothesis that the extent of cell death occurring in the HIV1producing cell cultures may account for these results. We did so by investigating whether inducing cell death in the NL4-3transfected HeLa cell cultures, prior to virus collection and purification, may be sufficient to endow these viruses with a capacity to kill unstimulated primary CD4 $+\mathrm{T}$ cells. We transfected HeLa cells with either the NL4-3 vector or the control vector, and purified, in one-half of the cultures, the supernatants $48 \mathrm{~h}$ later as usual. In the other half of the NL4-3and control-transfected HeLa cell cultures, we induced cell death either by UV irradiation (Figure $3 d$ ) or by serum deprivation (data not shown) $15 \mathrm{~h}$ before supernatant purification (33 $\mathrm{h}$ after transfection). In contrast with viruses purified from living NL4-3-transfected HeLa cells, the same concentration of viruses purified from dying NL4-3-transfected HeLa cells induced death in primary CD4 $+\mathrm{T}$ cells (Figure $3 d$ ). Supernatants from dying control HeLa cells did not affect CD4 + T-cell survival in the absence of virus addition (Figure 3d). Together, our findings indicated that (i) NL4-3 viruses were devoid by themselves of any significant capacity to induce death of unstimulated CD4 + T cell, and (ii) cellular and/or viral cofactors produced by dying NL4-3-producing cells were required to allow the viruses to induce CD4 + T-cell death. We then investigated whether such cofactors could only be released by dying HIV1-producing cells, or whether they may also be released by any dying cell that did not express HIV1. We incubated primary CD4 $+\mathrm{T}$ cells with viruses purified from living NL4-3-transfected HeLa cells, in the absence or presence of supernatant purified from either living or dying (UV-irradiated) control HeLa cells. Neither NL43 viruses purified from living HeLa cells nor supernatants from dying HeLa control cells affected CD4 + T-cell survival by themselves (Figure 3e), but their combination induced CD4 + T-cell death (Figure $3 e$ ). Supernatants purified from dying control HeLa cells or from dying control peripheral blood $T$ cells in which death had been induced by serum deprival showed the same complementation effect, allowing viruses produced by living NL4-3-transfected HeLa cells to cause CD4 + T-cell death (Figure 3e). Together, these findings indicated that the cellular cofactors released by dying cells did not require the dying cell to express HIV, but could be released by neighboring uninfected dying cells, including primary $T$ cells. Because we now had an in vitro model of HIV1-induced CD4 + T-cell death operating with NL4-3 viruses produced by transfected HeLa cells, we could address our previous questions about the potential role of the HIV1 Env in the induction of this death process.

\section{HIV1 Env and Nef proteins are not required for the killing of unstimulated primary $\mathrm{CD} 4+\mathrm{T}$ cells by HIV1 NL4-3 in the presence of cellular factors released by neighboring dying cells}

We purified viruses from living HeLa cells transfected for $48 \mathrm{~h}$ either with a vector encoding native NL4-3 or with a vector encoding NL4-3 deleted in its env gene (NL4-3/Aenv) in the absence or presence of cotransfection with a vector encoding the MuLV env gene to produce NL4-3 viruses pseudotyped with the amphotropic MuLV env gene (NL4-3/MuLVenv) (Figure $4 \mathrm{a})$. The purified viruses $(500 \mathrm{ng}$ p24/ml) were then incubated with unstimulated primary CD4 $+\mathrm{T}$ cells in the presence of supernatants purified from either living or dying (serum deprived) control HeLa cells. In the presence of supernatants from dying HeLa cells, NL4-3/Denv did not affect CD4 + T-cell survival, but NL4-3/MuLVenvinduced CD4 + Tcell death at levels that were not significantly different from those induced by native NL4-3 (Figure 4b). Thus, while the expression by NL4-3 of a retroviral Env protein was required for NL4-3 to induce CD4 + T-cell killing in the presence of cellular factors released by dying neighboring cells, there was no specific requirement for the expression by NL4-3 of an HIV1 Env protein. Because the MuLV Env uses a high-affinity $\mathrm{Na}^{+}$-dependent phosphate transporter as a receptor for entry into cells, ${ }^{43,44}$ these findings indicated that NL4-3 Envmediated CD4 and CXCR4 signaling were not required to cause CD4 + T-cell death. Rather, CD4 + T-cell death was a consequence of either a gp41-independent HIV1 fusion process with the cells or the entry of the HIV1 viral particles into the cells.

The Nef protein is present, in small amounts, in the viral particle, ${ }^{45}$ and has been reported to exert either pro- or antiapoptotic effects. ${ }^{46-49}$ To investigate the potential role of Nef, we used viruses purified from living HeLa cells transfected for $48 \mathrm{~h}$ with a vector encoding NL4-3 deficient

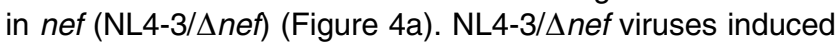
$\mathrm{CD} 4+\mathrm{T}$-cell death when incubated in the presence of supernatants from dying control HeLa cells, ruling out a requirement for Nef in the death process (Figure 4b). Together, our findings suggested that, in conjunction with cellular cofactor(s) released by dying cells, NL4-3 induces CD4 + T-cell death through a process that (i) does not require HIV1 Env-mediated CD4 or CXCR4 signaling, (ii) requires viral fusion or entry into the cells, and (iii) depends on viral factors other than the HIV1 Env and Nef proteins.

\section{CD95L released by dying cells is one of the cellular factors required by NL4-3 to induce death of primary CD4 $+\mathrm{T}$ cells}

We then investigated the potential nature of the cellular factor(s) released by dying cells that complemented NL4-3 in the induction of CD4 + T-cell killing. Flow cytometry analysis of the $100-450 \mathrm{~nm}$ fractions of the supernatants from either 

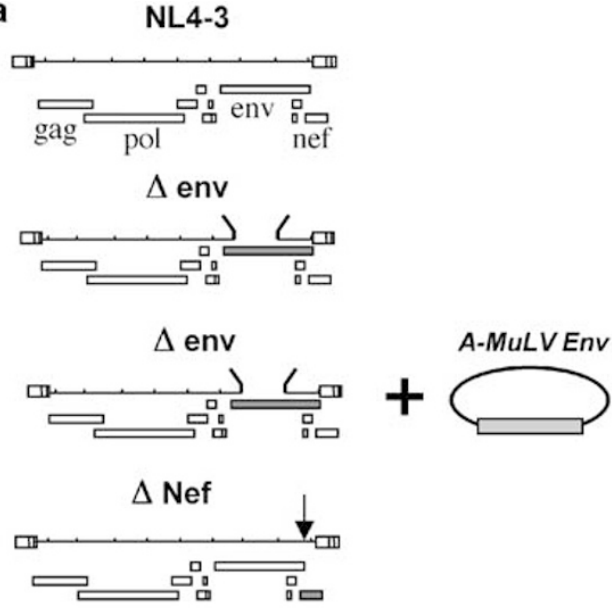

b

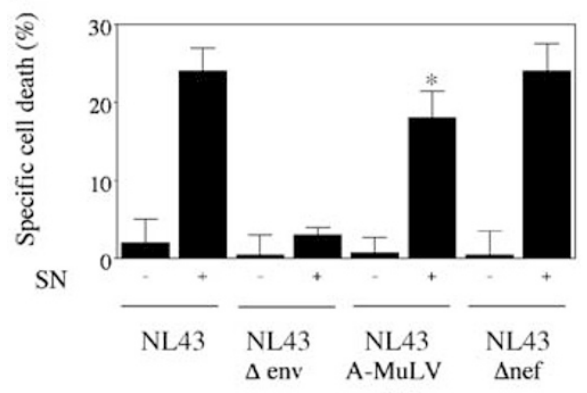

env

Figure 4 The NL4-3 Env and Nef proteins are not required for the killing of unstimulated primary $\mathrm{CD} 4+\mathrm{T}$ cells. (a) Schematic representation of the plasmids used to produce native NL4-3, env-deleted ( $\Delta$ env) and nef-deficient ( $\Delta$ nef) NL4-3, and amphotropic MuLVenv pseudotyped NL4-3 viruses. The NL4$3 / \Delta$ env plasmid is deleted in env (bp 6343-7611) (red). The NL4-3/Anef plasmid has been obtained by introducing a frameshift mutation at aa 35 (arrow), leading to a stop at aa 47 in the 206-aa-long Nef protein (red). The amphotropic MuLVenv pseudotyped NL4-3 viruses are obtained by cotransfecting the plasmid encoding NL4-3/Aenv and the plasmid encoding the MuLV amphotropic env (gray). (b) Purified unstimulated primary CD4 $+\mathrm{T}$ cells $\left(10^{6} / \mathrm{ml}\right)$ were incubated (i) with viruses $(500 \mathrm{ng} \mathrm{p} 24 / \mathrm{ml})$ purified $(100-450 \mathrm{~nm}$ fraction, see Materials and methods) from supernatants of living HeLa cells transfected for $48 \mathrm{~h}$ with either

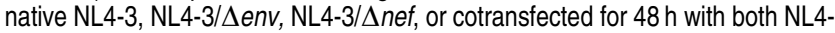
$3 / \Delta e n v$ and MuLV amphotropic env (NL4-3A-MuLV env) and (ii) an equal volume of supernatant purified (100-450 $\mathrm{nm}$ fraction) from either living, controltransfected HeLa cells ( $\mathrm{SN}-$ ) or from dying, serum-deprived, control-transfected HeLa cells (SN + ). Percentages of specific cell death after a 4-day culture were calculated as indicated in Materials and methods. Results are means \pm S.D. of one representative experiment out of three performed in triplicate. ${ }^{\star} P<0.01$ when compared to NL4-3/Aenv, and nonsignificant when compared to NL4-3

dying (serum deprived) control HeLa cells or dying (serum deprived) peripheral blood mononuclear cells indicated that they both contained large numbers of microvesicle-like particles, while the $100-450 \mathrm{~nm}$ fractions of the supernatants from living HIV1-transfected HeLa cells contained only very few particles (Figure $5 \mathrm{a}$ ). Dying ${ }^{50}$ or activated $^{51} \mathrm{~T}$ cells have been reported to release microvesicles of $100-200 \mathrm{~nm}$ in diameter carrying CD95 (Fas) ligand (CD95L), a member of the tumor necrosis factor (TNF) superfamily that interacts with the cell-surface death receptor CD95. ${ }^{52}$ To investigate whether CD95L might be present in the 100-450 nm fractions of dying cells, and might act as a cofactor of NL4-3 in our a

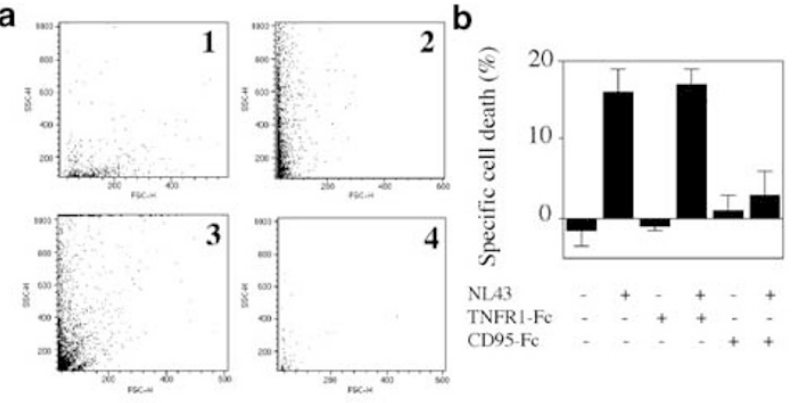

C

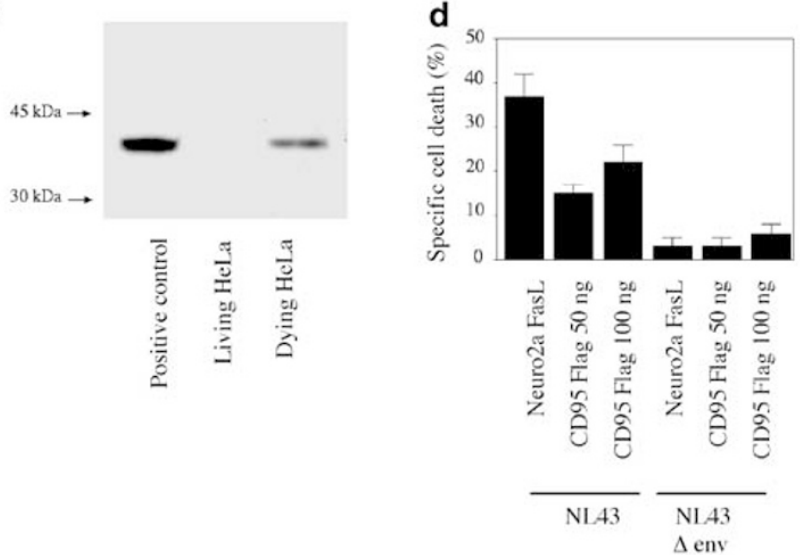

Figure 5 CD95L, released by dying cells, is one of the cellular factors required by NL4-3 to induce death of primary CD4 + T cells. (a) Purified supernatants $(100-450 \mathrm{~nm}$ fraction) from living NL4-3-transfected (1) or dying (serum deprived), control-transfected (2) HeLa cells $48 \mathrm{~h}$ after transfection, from dying (serum deprived) PBMC (3) or medium alone (4) were analyzed by flow cytometry using FSC/SSC parameters. (b) Purified unstimulated primary CD4 + T cells $\left(10^{6} / \mathrm{ml}\right)$ were incubated in the absence (NL4-3-) or presence (NL4-3 +) of viruses $(500 \mathrm{ng} \mathrm{p} 24 / \mathrm{ml})$ purified (100-450 nm fraction) from living NL4-3transfected HeLa cells and in the presence of purified supernatants $(100-450 \mathrm{~nm}$ fraction) from dying, control-transfected HeLa cells that had been preincubated for $1 \mathrm{~h}$ with either $\operatorname{CD} 95-\mathrm{Fc}(+)$ or TNFR1-Fc $(+)(10 \mu \mathrm{g} / \mathrm{ml}$ each) or with medium alone (-). (c) Western blot analysis, using a CD95L-specific $\mathrm{mAb}$, of the purified supernatants $(100-450 \mathrm{~nm}$ fractions) from living control-transfected HeLa cells $48 \mathrm{~h}$ after transfection (Living HeLa) or from dying, serum-deprived transfected HeLa cells $48 \mathrm{~h}$ after transfection (Dying HeLa), or of total Jurkat Tcell line extracts (Positive control). The $39-40 \mathrm{kDa}$ band corresponds to the described MW of the unprocessed, microvesicle-bound form of CD95L. ${ }^{52,56}$ (d) Purified unstimulated primary CD4 $+\mathrm{T}$ cells $\left(10^{6} / \mathrm{ml}\right)$ were incubated with viruses ( $500 \mathrm{ng} \mathrm{p} 24 / \mathrm{ml}$ ) purified from living HeLa cells transfected with NL4-3 or with NL4-3/Aenv, and with either supernatants from the Neuro-2a FasL cell line (Neuro-2a FasL), which contain microvesicle-bound, unprocessed CD95L, ${ }^{57}$ or with soluble recombinant (sr)FLAG-tagged CD95L (50 or $100 \mathrm{ng} / \mathrm{ml}$ ) crosslinked by FLAG-specific antibody (CD95L Flag). Percentages of specific cell death after a 4-day culture shown in (b, d) were calculated as indicated in Materials and methods. Results shown in (b, d) are means \pm S.D. of one representative experiment out of three (b) and two (d), each performed in triplicate

model, we incubated unstimulated primary CD4 + T cells with both viruses purified from living NL4-3-transfected HeLa cells and supernatants from dying (serum deprived) control HeLa cells, in the absence or presence of either a CD95-Fc chimeric immunoglobulin that prevents CD95L from binding CD95 or a TNFR1-Fc chimeric immunoglobulin that prevents TNF from binding both TNFR1 and R2 receptors. CD95-Fc, but not TNF $\mathrm{R} 1-\mathrm{Fc}$, prevented induction of CD4 + T-cell death (Figure $5 \mathrm{~b}$ ). Cells can release CD95L either as a soluble, metalloprotease processed form of $26 \mathrm{kDa}$, or as a microvesicle-bound, 
unprocessed form of 33-40 kDa, likely representing differently glycosylated forms of the CD95L molecule. ${ }^{51,53-55}$ Western blot analysis of the purified supernatants of living or dying (serum deprived) control HeLa cells, using a CD95L-specific antibody, showed the presence of a 39-40 kDa CD95L in the latter (as in the positive control Jurkat cell cytoplasmic lysates) and no detectable CD95L in the former (Figure $5 \mathrm{c}$ ). To further investigate the potential role of CD95L, we incubated CD4 + T cells with supernatants from the Neuro-2a FasL cell line, which contain microvesicle-bound, unprocessed CD95L released by these cells. ${ }^{55}$ Neuro-2a FasL supernatants induced high levels of CD4 $+\mathrm{T}$-cell death in the presence of NL4-3 viruses purified from living transfected HeLa cells, but not in the presence of NL4-3/Aenv viruses (Figure $5 d$ ). The microvesicle-bound, unprocessed form of CD95L has a higher aggregation degree, and hence death signaling efficiency, than its soluble $26 \mathrm{kDa}$ form. ${ }^{54}$ However, a similar aggregation degree can be achieved by crosslinking soluble recombinant (sr) FLAG-tagged CD95L, using FLAG-specific antibodies. ${ }^{54}$ We incubated CD4 + T cells with either FLAG-specific antibody-crosslinked soluble recombinant FLAG-tagged CD95L (srCD95L), noncrosslinked srCD95L, or the FLAGspecific antibody alone, in the presence of either NL4-3 or NL4-3/Aenv viruses purified from living transfected HeLa cells. Crosslinked srCD95L synergized in a dose-dependent manner with NL4-3, but not with NL4-3/Aenv in inducing CD4 + T-cell killing (Figure 5d), while neither nonaggregated srCD95L nor the anti-FLAG antibody affected CD4 + T-cell survival (data not shown). In contrast with the supernatants from dying cells, however, both Neuro-2a FasL supernatants and crosslinked srCD95L induced some background level of CD4 + T-cell death in the absence of NL4-3 viruses (data not shown). Thus, it is possible that the concentrations of bioactive CD95L present in the dying cell supernatants that we purified are lower than the concentrations of crosslinked srCD95L (50 and $100 \mathrm{ng} / \mathrm{ml}$ ) that we used and/or that the aggregation degree of CD95L present in the dying cell supernatants is lower than that induced by the FLAG-specific antibody. Alternately, it is possible that some yet unidentified additional cellular factor(s), released by the dying cells, cooperate(s) with suboptimal concentrations of CD95L present in the dying cell supernatants to complement HIV1 in inducing CD4 + T-cell killing. While these possibilities remain to be investigated, our findings strongly suggest that the engagement of the CD95 receptor on unstimulated primary $\mathrm{CD} 4+\mathrm{T}$ cells by microvesicle-bound CD95L released by neighboring dying cells is one of the cellular factors that cooperate with HIV1 in inducing death of these CD4 + T cells.

\section{Discussion}

Here we identify a novel, indirect process of HIV1-mediated bystander CD4 + T-cell killing that does not require productive infection of the target cells, but depends on the presence of neighboring dying cells. Previously proposed mechanisms for HIV1-mediated CD4 + T cells cell death induction include the killing of productively infected CD4 + T cells caused either by direct viral cytopathic effects or by antiviral cytotoxic $T$ lymphocytes; ${ }^{5-7}$ the killing of bystander $\mathrm{CD} 4+\mathrm{T}$ cells caused, in the absence of productive infection, by the binding or the entry of viral proteins released by infected cells or proteins present on or inside the viral particles; ${ }^{1,2,8-10}$ and the activation-induced cell death of various uninfected immune cells, including CD4 + T cells, caused by excessive, ongoing immune activation induced by high persistent viral antigen load. ${ }^{1,2,4,8,9}$ An important implication of our findings is that each of these viral- or immune-mediated CD4 + T-cell killing mechanisms might not only contribute to CD4 $+\mathrm{T}$-cell loss through a simple cumulative process; rather the extent of cell death occurring in vivo during HIV1 infection, whatever its causal mechanism and the nature of the dying cells, may by itself allow, above a given threshold and in the presence of a sufficient amount of HIV1 particles, the induction of an additional, synergic pathogenic mechanism causing further bystander CD4 + T-cell killing. Our findings may thus help conciliate the often opposed views on the respective contributions of viral load and immune activation to progression toward AIDS, ${ }^{4}$ since they provide a framework suggesting that viral production, viral cytopathic effects, immunemediated cell killing, and activation-induced cell death might all contribute to the induction of a common amplification process of $\mathrm{CD} 4+\mathrm{T}$-cell depletion, which requires the presence of both HIV1 particles and dying cells.

Several in vitro findings have suggested that the HIV1 Env protein is a major candidate for uninfected bystander CD4 + T-cell killing through death signaling triggered by binding to its cell-surface receptors. ${ }^{20-22,24-26}$ While our results confirm previous findings indicating that antibody-mediated engagement of CD4 or CXCR4 can indeed induce CD4 + T-cell death, ${ }^{27-30}$ they also indicate that the interactions of the HIV1 Env protein with CD4 and/or CXCR4 are not responsible for the killing by HIV1 particles of unstimulated, noncycling primary CD4 + T cells. Rather, in the presence of cellular factors released by dying cells, CD4 + T-cell killing required the presence of the Env protein on the viral particle simply because of a requirement for HIV1 postbinding fusion or entry into the CD4 + T cells. Accordingly, while the lack of Env prevented HIV1 from causing CD4 + T-cell death, pseudotyped HIV1 particles expressing the MuLV amphotropic Env induced CD4 + T-cell killing in the presence of cellular factors released by dying cells. Because the amphotropic Env of MuLV allows entry into cells through a high-affinity $\mathrm{Na}^{+}$dependent phosphate transporter, ${ }^{43,44}$ our results imply that neither HIV1 gp120 Env interaction with CD4 and/or CXCR4, nor HIV1 gp41 Env-mediated fusion is required for the induction of CD4 + T-cell death in our in vitro model. Our findings also indicate that the Nef protein, present in small amounts in the HIV1 particles ${ }^{45}$ and reported to either induce or repress cell death, ${ }^{46-49}$ is not required for the killing of noncycling CD4 + T cells in our model. Tat, another HIV1 protein that has been found to either induce ${ }^{21,56,57}$ or repress ${ }^{58}$ cell death in vitro, is not present in the viral particles, but is released by HIV1-producing cells. ${ }^{59}$ Therefore, it is possible that Tat was present in the $100-450 \mathrm{~nm}$ fractions purified from supernatants of living, HIV1-transfected HeLa cells that we used as a source of virus. However, because both the wild type and $\Delta e n v$ HIV1 plasmids that we used encoded tat, and because the $\Delta e n v$ HIV1 particles did not 
affect CD4 + T-cell survival in the presence of cellular factors released by dying cells, our data suggest that Tat does not play a significant role in CD4 + T-cell killing in our model. Interestingly, it was recently reported that the direct cytopathic effect of HIV1 in cycling, productively infected primary CD4+ $T$ cells does not require HIV Env interactions with its cellsurface receptors nor the presence of the Nef protein. ${ }^{60}$ Whether the HIV1 factors required for the direct cytopathic effect of HIV1 in productively infected CD4 + T cells $^{60}$ and for the indirect, bystander CD4 + T-cell killing process that we identified here are, or not, the same is an important question that remains to be addressed.

The $100-450 \mathrm{~nm}$ fractions of supernatants from dying cells that cooperated with HIV1 in inducing CD4 + T-cell death in our model contained microvesicles and CD95L, the latter being required for $\mathrm{CD} 4+\mathrm{T}$-cell killing. Microvesicles, ${ }^{61}$ presumably released by dying cells in vivo, and soluble CD95L, ${ }^{62}$ which might either be released by activated or dying cells, have each been detected by independent studies in the plasma from HIV1-infected persons. ${ }^{61,62}$ Whether such soluble CD95L is expressed by the microvesicles in the peripheral blood from HIV1-infected persons, and is aggregated to a degree that allows it to complement HIV1 in inducing CD4 T-cell killing is an important question that remains to be investigated.

The X4-tropic HIV1 isolates that use the CXCR4 chemokine receptor as a coreceptor for entry into cells begin to predominate in HIV1-infected persons at the late stages of infection that precede the onset of AIDS. ${ }^{63}$ In contrast, the R5tropic HIV1, which use the CCR5 chemokine receptor as a coreceptor for entry into cells, predominate during most of the asymptomatic phase of HIV1 infection. ${ }^{63}$ In vivo, CD4+ T cells express both CCR5 and CXCR4. However, in vitro isolation of peripheral blood CD4 + cells causes a rapid, almost complete, and persisting downregulation of CCR5 expression, although not affecting CXCR4 expression. ${ }^{41}$ Because the HIV-mediated CD4 + T-cell killing process that we identified in vitro required HIV1 entry into the CD4 + T cells, the lack of killing activity of the R5-tropic HIV1 isolates might simply have been due to their inability to enter the CD4 + T cells. Our findings indicated, however, that the killing activity of HIV1 in our model did not depend on the particular genetic make-up of their Env, since effective killing was induced by MuLV-Env pseudotyped HIV1 particles. Thus, because the major genetic difference between X4-tropic and R5-tropic HIV1 isolates concerns their Env, which dictates their coreceptor usage, ${ }^{63}$ our findings suggest the possibility that in conditions in which CCR5 is expressed, R5-tropic HIV1s might induce the same CD4 + T-cell killing process as X4-tropic HIV1s, when in the presence of dying cells. Assessing whether this is indeed the case might have important implications for our understanding of AIDS pathogenesis. Provided that the CD4 + T-cell death mechanism we identified in vitro also operates in vivo, our findings imply that therapeutic strategies aimed at reducing the extent of T-cell activation and T-cell death in HIV1-infected persons might have unsuspected synergic effects with anti-retroviral therapy by reducing the amount of cellular cofactors below the threshold required for the induction by HIV1 particles of this indirect, bystander CD4 + T-cell depletion process.
Finally, our findings also raise the broader question of the possible existence of similar synergic killing processes involving neighboring dying cells in the pathogenesis of other infectious pathogens.

\section{Materials and Methods}

\section{Reagents and antibodies}

Murine monoclonal antibodies (mAbs) with the following specificities were used: CD4 (Leu3a; Becton Dickinson, Mountain View, CA, USA); CD14, CD19, CD56, and CD8 (PharMingen, San Diego, CA, USA); CXCR4 (clone 12G5) and CCR5 (clone 45531.111) (R\&D System, Abingdon, UK); and isotype controls. Labeled mAbs were FITC-labeled CD4-specific, PElabeled CD8-specific, and PC5-labeled CD14-specific mAbs (Becton Dickinson); FITC-labeled CXCR4- and CCR5-specific mAbs (R\&D System), and isotype controls. For Western blotting, we used a mouse monoclonal CD95L-specific (F 37720, IgG1 isotype; Transduction Laboratories, San Diego, CA, USA) and a horseradish-peroxidaseconjugated sheep anti-mouse IgG $F\left(a^{\prime}\right) 2$ fragment (NA9310; Amersham International). Soluble decoy proteins were human CD95-Fc immunoglobulin fusion protein (that binds $\mathrm{CD} 95 \mathrm{~L}$ ) purchased from Alexis Corporation (San Diego, CA, USA), and TNFR1-Fc (that binds TNF and lymphotoxin) purchased from R\&D System; the reverse transcriptase inhibitors AZT and ddl were purchased from Sigma (St. Quentin, France); the G-protein inhibitor Bordetella pertussis toxin was from Alexis Corporation; and the chemokines SDF1 $\alpha$, MIP $1 \alpha$, and RANTES were from R\&D System. Other reagents were FITC- and PE-labeled annexin V (R\&D System), DiOC6 (Molecular Probes, Eugenes, OR, USA), and Trypan blue dye (Sigma). Soluble recombinant human $\mathrm{CD} 4$ protein was a gift from $\mathrm{D}$ Klatzmann (CNRS ERS 107-CERVI, CHU Pitié-Salpetrière, Paris, France); the (FLAG)-tagged CD95L and the FLAG-specific antibody were kindly provided by $P$ Schneider (Institute of Biochemistry, Epalinges, Switzerland).

\section{Preparation of purified primary CD4 $+\mathbf{T}$ cells}

Heparinized venous peripheral blood was obtained from HIV-seronegative healthy donors (Centre de Transfusion Sanguine, Hôpital Bichat). PBMC were isolated from these samples by Ficoll-Hypaque gradient centrifugation density (Pharmacia) and then cultured in RPMI 1640 (Gibco/BRL, Gaithersburg, MD, USA) supplemented with $10 \%$ heat-inactivated fetal bovine serum (Summit Biotechnology, Greeley, CO, USA), $2 \mathrm{mM} \mathrm{L-}$ glutamine, $1 \mathrm{mM}$ sodium pyruvate, and penicillin/streptomycin (Gibco). After $24 \mathrm{~h}$ culture in plastic flasks, nonadherent cells were removed and $\mathrm{CD}^{+}{ }^{+} \mathrm{T}$ cells were purified by negative selection. Cells were incubated with a cocktail of CD14, CD19, CD56, and CD8 mAbs $\left(1 \mu \mathrm{g} / 10^{6}\right.$ cells expressing the corresponding cell-surface molecule) and cultured for $2 \mathrm{~h}$ on a bidirectional rocking shaker at $4^{\circ} \mathrm{C}$. Then, magnetic beads coated with anti-mouse IgG (Dynal, Lake Success, NY, USA) were added to the cells, which were cultured for one more hour at $4^{\circ} \mathrm{C}$. A magnet was used to retain cells covered with antibody-beads complex, and nonattached purified $\mathrm{CD} 4^{+} \mathrm{T}$ cells were collected. The purity of the remaining cell population assessed by flow cytometry with a FACScan (Becton Dickinson), using FITC-labeled CD4-specific, PE-labeled CD8-specific, PC5-labeled CD14-specific mAbs and isotype controls, was regularly found to be at least $95 \%$. When so indicated, cell-surface expression of chemokine receptor on the purified CD4 $+\mathrm{T}$ cells was assessed by flow cytometry analysis using FITC-labeled CXCR4-specific and CCR5-specific 
mAbs and isotype controls, after incubation of the antibodies with the $\mathrm{CD} 4+\mathrm{T}$ cells for $1 \mathrm{~h}$ at $4^{\circ} \mathrm{C}$.

\section{Chemotaxis assay}

Purified CD4 ${ }^{+} \mathrm{T}$ cells were resuspended in ML10 at a concentration of $1 \times 10^{6} / \mathrm{ml}$. Cells $(100 \mu \mathrm{l})$ were then added to the top chamber of a Transwell chamber $(6.5 \mathrm{~mm}$ diameter, $8 \mu \mathrm{m}$ pore size with polycarbonate membrane, Corning Costar) while either the SDF1 $\alpha$, MIP1 $\alpha$ or RANTES chemokines $(25 \mathrm{nM})$ or medium alone was added to the lower chamber. Cells were allowed to migrate for $2 \mathrm{~h}$ at $37^{\circ} \mathrm{C}$ in an atmosphere of $5 \% \mathrm{CO}_{2}$, then migrated cells were collected in the lower chamber and counted by flow cytometry analysis using high fluiding speed for $4 \mathrm{~min}$.

\section{Cells and culture conditions}

The purified primary CD4 + T cells, the Neuro2a-FasL cell line ${ }^{55}$ (kindly provided by A Fontana, Department of Internal Medicine, Zurich, Switzerland), the CEM-HIV1 LTR human T-lymphoblastoid cell line, which expresses both CD4 and CXCR4, and the CEM-GFP-CCR5 ${ }^{+}$cell line (generous gift from A Gervaix, Geneva University, Geneva, Switzerland), which encodes the green fluorescent protein (GFP) under the control of the HIV-1NL4-3 LTR promoter, allowing a rapid determination of viral production, ${ }^{64}$ and expresses the human CCR5 chemokine receptor following stable transfection, were all cultured in RPMI 1640 (Gibco/BRL, Gaithersburg, MD, USA) supplemented with 10\% heatinactivated fetal bovine serum (Summit Biotechnology, Greeley, CO, USA), $2 \mathrm{mM}$ L-glutamine, $1 \mathrm{mM}$ sodium pyruvate, and penicillin/ streptomycin (Gibco). HeLa cells were cultured in DMEM supplemented with $10 \%$ FCS and antibiotics.

\section{Virus preparation}

Virus stocks of X4-tropic HIV1 laboratory isolates (LAI, R9, NL4-3) were produced by infecting either CEM cells or CEM-HIV1 LTR-GFP-CCR5 ${ }^{+}$ cells, as indicated. Virus stocks of R5-tropic HIV1 laboratory isolates (Ada, $\mathrm{BaL})$ were produced by infecting the CEM-HIV1 LTR-GFP-CCR5 ${ }^{+}$cells. Viruses were collected at the peak of viral production, after centrifugation of the culture supernatants $(800 \times g$ for $10 \mathrm{~min})$, followed, when so indicated, by filtration through $0.45-0.1 \mu \mathrm{m}$ pore size filters, retaining the $100-450 \mathrm{~nm}$ fractions, and viral titers were normalized by p24 ELISA. In some experiments, viruses were collected from infected CEM-HIV1 LTRGFP-CCR5 ${ }^{+}$cells at days 4,8 , or 50 after infection, and purified as indicated above. When so indicated, NL4-3 viruses were also obtained by transfection of HeLa cells. Subconfluent HeLa cells were transfected with $30 \mu \mathrm{g}$ of the full-length plasmid DNA encoding the X4-tropic virus NL4-3, using the calcium phosphate precipitation method. When so indicated, HeLa cells were transfected with $30 \mu \mathrm{g}$ of plasmid DNA encoding either the NL4-3/Aenv (deleted in env) that carries a deletion of its env gene from bp 6343 to bp 7611 (kindly provided by K Strebel, NIH, MD, USA), or the NL4-3/Anef (deficient in nef) (kindly provided by O Schwartz, Institut Pasteur, Paris, France), obtained, as previously reported, by introducing a frameshift mutation at amino acid (aa) 35, leading to a premature stop at aa 47 of the 206-aa-long Nef protein. ${ }^{65}$ MuLV amphotropic env pseudotyped NL4-3 viruses were obtained by cotransfecting HeLa cells

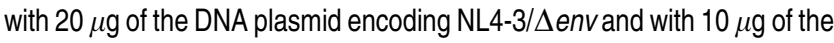
DNA plasmid SV-A-MLV-env encoding the MuLV amphotropic env (kindly provided by N Landau, Aaron Diamond Center, New York, NY, USA ${ }^{66}$ ). Control HeLa cells were transfected with the DNA plasmid encoding the control vector ( $p$ Blue Script). Cells were washed with PBS $12 \mathrm{~h}$ after transfection, and $20 \mathrm{ml}$ of fresh DMEM $+10 \%$ FCS were added. At $48 \mathrm{~h}$ after transfection, culture supernatants were collected, clarified by centrifugation $(800 \times g$ for $10 \mathrm{~min})$, filtered through a $0.45 \mu \mathrm{m}$ filter and concentrated using centriconplus (Millipore) $0.1 \mu \mathrm{m}$ filters retaining the $100-450 \mathrm{nM}$ fractions, according to the manufacturer's protocol. Viral production was assessed by measuring p24 antigen concentrations using p24 ELISA (NEN, Life Science Products, Boston, MA, USA) and viral titers were normalized by p24 antigen concentration analysis using p24 ELISA.

\section{Cell death induction}

When so indicated, cell death was induced in transfected HeLa cells $33 \mathrm{~h}$ after transfection either by UV irradiation under a UV light, or by serum deprivation, culture medium being removed and replaced by RPMI 1640 . At $48 \mathrm{~h}$ after transfection, the supernatant was collected, clarified by centrifugation $(800 \times g$ for $10 \mathrm{~min})$ and filtered through $0.45-0.1 \mu \mathrm{m}$ pore size filters as described above. When so indicated, cell death was also induced in PBMC collected from healthy donors by culturing them in RPMI 1640 in the absence of serum. After 7 days, the supernatants were collected and purified as described above.

\section{Measurement of cell death in purified primary CD4 + T-cell cultures}

Purified primary $\mathrm{CD}^{+}{ }^{+} \mathrm{T}$ cells $\left(10^{6} / \mathrm{ml}\right)$ were incubated with either viruses (500 ng p24/ml), CD4-specific (Leu3a), CXCR4-specific, or CCR5-specific $\mathrm{mAbs}$ or isotype controls (10 $\mu \mathrm{g} / \mathrm{ml}$ added in solution), or the recombinant chemokine SF1 $\alpha(100 \mathrm{nM})$. In some experiments, viruses were preincubated for $1 \mathrm{~h}$ with soluble recombinant human CD4 protein (either 0.1 or $10 \mu \mathrm{g} / \mathrm{ml}$ ), prior to incubation with the $\mathrm{CD} 4^{+} \mathrm{T}$ cells. Incubation of $\mathrm{CD}^{+}{ }^{+} \mathrm{T}$ cells with plate-immobilized antibody was performed by coating plates with $10 \mu \mathrm{g} / \mathrm{ml}$ of CD4-, CXCR4-, or CCR5-specific mAbs or an isotype control in Tris- $\mathrm{HCl}$ buffer, $\mathrm{pH} 9.6$, overnight at $4{ }^{\circ} \mathrm{C}$, and washing, prior to the addition of CD4 + T cells to the plate. When so indicated, CD4 + T cells $\left(10^{6} / \mathrm{ml}\right)$ were incubated with the filtered $100-450 \mathrm{~nm}$ fraction of living or dying HeLa cell supernatants, or of dying PBMC supernatants, in the absence or presence of viruses.

After 4 days of culture in vitro, cells were collected and counted in triplicate by light microscopy using Trypan blue dye exclusion, and FITClabeled annexin V. Absolute numbers of living cells (total number of cells counted by microscopy - number of dying cells) was determined for each condition. The percentage of specific cell death induced by viruses or antibody was calculated as follows: 100 -(number of living cells in the viruses or antibody condition/number of living cells in the medium condition) $\times 100$.

\section{Cell cycle analysis}

Purified primary $\mathrm{CD} 4+\mathrm{T}$ cells $\left(10^{6} / \mathrm{ml}\right)$ were incubated with either supernatant from uninfected CEM cells or LAI virus $(500 \mathrm{ng}$ p24/ml) produced by infected CEM cells, in the absence or presence of $1 \mu \mathrm{g} / \mathrm{ml}$ PHA-P (Sigma) (100 Ul/ml IL2). After 4 days of culture, cell cycle was assessed by flow cytometry analysis using propidium iodide staining as previously described. ${ }^{67}$

\section{Western blotting}

Cells (Jurkat cells) or the filtered $100-450 \mathrm{~nm}$ fraction of living or dying HeLa cell supernatants were incubated in SDS lysis buffer, boiled for 
$10 \mathrm{~min}$, and centrifuged for $15 \mathrm{~min}$ at room temperature. Total protein was measured using the DC Protein Assay (Bio Rad Laboratories, Hercules, CA, USA). Equal amounts of proteins were boiled for $5 \mathrm{~min}$ in $2 \times$ Laemmli sample buffer with 2-bME and run on a $4 / 20 \%$ polyacrylamide gel (Bio-Rad). Proteins were transferred to a PVDF membrane (Bio Rad), and immunoblotted with a mouse CD95L-specific mAb and a horseradishperoxidase-conjugated sheep anti-mouse $\lg G\left(a^{\prime}\right) 2$ fragment, followed by enhanced chemiluminescence (RPN 2109; Amersham International).

\section{Acknowledgements}

We thank A Fontana (Department of Internal Medicine, Zurich, Switzerland), A Gervaix (University of Geneva, Switzerland), D Klatzmann (CNRS ERS 107-CERVI, CHU Pitié Salpetrière, Paris, France), N Landau (Aaron Diamond Center, New York, NY, USA), P Schneider (Institute of Biochemistry, Epalinges, Switzerland), O Schwartz (Institut Pasteur, Paris, France), and K Strebel (NIH, Bethesda, MD, USA) for the generous gift of valuable reagents, and $\mathrm{F}$ Clavel (INSERM U552, CHU Bichat, Paris, France) for discussion. This work was supported by INSERM, Université Paris 7, Université Paris 7 Valorisation, AP-HP, and grants from ANRS, ECS, FRM, and EFG (to JCA), and doctoral fellowships from ANRS (to JDL), ECS (to FP), and DGA and FRM (to DA).

\section{References}

1. Shearer GM (1998) HIV-induced immunopathogenesis. Immunity 9: 587-593

2. Badley AD, Pilon AA, Landay A and Lynch DH (2000) Mechanisms of HIVassociated lymphocyte apoptosis. Blood 96: 2951-2964

3. Mc Cune JM (2001) The dynamics of CD4+ T-cell depletion in HIV disease. Nature 410: 974-979

4. Grossman Z, Meier-Schellersheim M, Sousa A, Victorino R and Paul W (2002) CD4+ T-cell depletion in HIV infection: are we closer to understanding the cause? Nat. Med. 8: 319-323

5. Ho DD, Neumann AU, Perelson AS, Chen W, Leonard JM and Markowitz M (1995) Rapid turnover of plasma virions and CD4+ lymphocytes in HIV-1 infection. Nature 373: 123-126

6. Wei X, Ghosh SK, Taylor ME, Johnson VA, Emini EA, Deutsch P, Lifson JD, Bonhoeffer S, Nowak MA, Hahn BH, Saag MS and Shaw GM (1995) Viral dynamics in HIV-1 infection. Nature 373: 117-122

7. Perelson AS, Neumann AU, Markowitz M, Leonard JM and Ho DD (1996) HIV1 dynamics in vivo: virion clearance rate, infected-cell life span, and viral generation time. Science 271: 1582-1586

8. Ameisen JC and Capron A (1991) Cell dysfunction and depletion in AIDS: the programmed cell death hypothesis. Immunol. Today 12: 102-105

9. Ameisen JC, Estaquier J, Idziorek T and De Bels F (1995) Programmed cell death and AIDS: significance, perspectives and unanswered questions. Cell Death Differ. 2: 9-22

10. Ameisen JC (1998) HIV: setting death in motion. Nature 395: 117-119

11. Finkel TH, Tudor-Williams G, Banda NK, Cotton MF, Curiel T, Monks C, Baba TW, Ruprecht RM and Kupper A (1995) Apoptosis occurs predominantly in bystander cells and not in productively infected cells of HIV- and SIV-infected lymph nodes. Nat. Med. 1: 129-134

12. Muro-Cacho CA, Pantaleo G and Fauci AS (1995) Analysis of apoptosis in lymph nodes of HIV-infected persons. Intensity of apoptosis correlates with the general state of activation of the lymphoid tissue and not with the stage of disease or viral burden. J. Immunol. 154: 5555-5566

13. Badley AD, Dockrell DH, Algeciras A, Ziesmer S, Landay A, Lederman MM, Connick E, Kessler H, Kuritzkes D, Lynch DH, Roche P, Yagita H and Paya CV (1998) In vivo analysis of Fas/FasL interactions in HIV-infected patients. J. Clin. Invest. 102: 79-87

14. Rosok B, Brinchmann JE, Stent G, Bjerknes R, Voltersvik P, Olofsson J and Asjo B (1998) Correlates of apoptosis of CD4+ and CD8+ T cells in tonsillar tissue in HIV type 1 infection. AIDS Res. Hum. Retrov. 14: 1635-1643
15. Wykrzykowska JJ, Rosenzweig M, Veazey RS, Simon MA, Halvorsen K, Desrosiers RC, Johnson RP and Lackner AA (1998) Early regeneration of thymic progenitors in rhesus macaques infected with SIV. J. Exp. Med. 11: 1767-1778

16. Jekle A, Keppler O, De Clercq E, Schols D, Weinstein M and Goldsmith MA (2003) In vivo evolution of HIV1 toward increased pathogenicity through CXCR4-mediated killing of uninfected CD4+ T cells. J. Virol. 77: 5846-5854

17. Gougeon M-L, Garcia S, Heeney J, Tschopp R, Lecoeur H, Guétard D, Rame V, Dauguet C and Montagnier L (1993) Programmed cell death in AIDS-related HIV and SIV infections. AIDS Res. Hum. Retrov. 9: 553-563

18. Estaquier J, Idziorek T, De Bels F, Barré-Sinoussi F, Hurtrel B, Aubertin AM, Venet A, Mehtali M, Muchmore E, Michel P, Mouton Y, Girard M and Ameisen JC (1994) Programmed cell death and AIDS: the significance of T-cell apoptosis in pathogenic and non pathogenic primate lentiviral infections. Proc. Natl. Acad. Sci. USA 91: 9431-9435

19. Estaquier J, Tanaka M, Suda T, Nagata S, Golstein P and Ameisen JC (1996) Fas-mediated apoptosis of CD4+ and CD8+ T cells from HIV-infected persons: differential in vitro preventive effect of cytokines and protease antagonists. Blood 87: 4959-4966

20. Banda NK, Bernier J, Kurahara DK, Kurrle R, Haigwood N, Sekaly RP and Finkel TH (1992) Crosslinking CD4 by HIV gp120 primes T cells for activationinduced apoptosis. J. Exp. Med. 176: 1099-1106

21. Westendorp MO, Frank R, Ochsenbauer C, Stricker K, Dhein J, Walczak H, Debatin KM and Krammer PH (1995) Sensitization of T cells to CD95-mediated apoptosis by HIV-1 Tat and gp120. Nature 375: 497-500

22. Accornero P, Radrizzani M, Delta D, Gerosa F, Kurrie R and Colombo MP (1997) Differential susceptibility to HIV gp120-sensitized apoptosis in CD4+ Tcell clones with different T-helper phenotypes: role of CD95/CD95L interactions. Blood 89: 558-569

23. Kameoka M, Kimura T, Zheng YH, Suzuki S, Fujinaga K, Luftig RB and Ikuta $K$ (1997) Protease-defective gp120-containing HIV-1 particles induce apoptosis more efficiently than does wild-type virus or recombinant gp120 protein in healthy donor-derived peripheral blood T cells. J. Clin. Microbiol. 35: 41-47

24. Ohnimus $H$, Heinkelein M and Jassoy C (1997) Apoptotic cell death upon contact of CD4+ T lymphocytes with HIV glycoprotein-expressing cells is mediated by caspases but bypasses CD95 (Fas/Apo-1) and TNF. J. Immunol. 159: 5246-5252

25. Blanco J, Jacotot E, Cabrera C, Cardona A, Clotet B, De Clercq E and Este JA (1999) The implication of the chemokine receptor CXCR4 in HIV-1 envelope protein-induced apoptosis is dependent of the $G$ protein-mediated signaling. AIDS 13: 909-917

26. Blanco J, Barretina J, Henson G, Bridger G, De Clercq E, Clotet B and Este JA (2000) The CXCR4 antagonist AMD3100 efficiently inhibits cell-surfaceexpressed HIV-1 envelope-induced apoptosis. Antimicrob. Agents Chemother. 44: $51-56$

27. Desbarats J, Freed JH, Campbell PA and Newell MK (1996) Fas (CD95) expression and death-mediating function are induced by CD4 cross-linking on CD4+ T cells. Proc. Natl. Acad. Sci. USA 93: 11014-11018

28. Hashimoto F, Oyaizu N, Kalyanaraman VS and Pahwa S (1997) Modulation of Bcl-2 protein by CD4 cross-linking: a possible mechanism for lymphocyte apoptosis in HIV infection and for rescue of apoptosis by IL-2. Blood 90: 745-753

29. Algeciras A, Dockrell FH, Lynch DH and Paya CV (1998) CD4 regulates susceptibility to Fas ligand- and TNF-mediated apoptosis. J. Exp. Med. 187: $711-720$

30. Berndt C, Mopps B, Angermuller S, Gierschik P and Krammer PH (1998) CXCR4 and CD4 mediate a rapid CD95-independent cell death in CD4+ T cells. Proc. Natl. Acad. Sci. USA 95: 12556-12561

31. Jekle A, Keppler OT, De Clercq E, Schols D, Weinstein M and Goldsmith MA (2003) In vivo evolution of human immunodeficiency virus type 1 toward increased pathogenicity through CXCR4-mediated killing of uninfected CD4+ T cells. J. Virol. 77 : 5846-5854

32. Martin SJ, Matear P and Vyakarnam A (1994) HIV-1 infection of human CD4+ T cells in vitro. Differential induction of apoptosis in these cells. J. Immunol. 152: 330-342

33. Esser MT, Bess Jr. JW, Suryanarayana K, Chertova E, Marti D, Carrington M, Arthur LO and Lifson JD (2001) Partial activation and induction of apoptosis in CD4(+) and CD8(+) T lymphocytes by conformationally authentic noninfectious HIV1. J. Virol. 75: 1152-1164 
34. Ducrey-Rundquist O, Guyader M and Trono D (2002) Modalities of IL7-induced HIV permissiveness in quiescent T lymphocytes. J. Virol. 76: 9103-9111

35. Swingler S, Brichacek B, Jacque JM, Ulich C, Zhou J and Stevenson M (2003) HIV1 Nef intersects the macrophage CD40L signalling pathway to promote resting-cell infection. Nature 424: 213-219

36. Dalgleish AG, Thomson BJ, Chanh TC, Malkovsky M and Kennedy RC (1987) Neutralisation of HIV isolates by anti-idiotypic antibodies which mimic the T4 (CD4) epitope: a potential AIDS vaccine. Lancet li: 1047-1050

37. Benkirane M, Corbeau P, Housset V and Devaux C (1993) An antibody that binds the immunoglobulin CDR3-like region of the CD4 molecule inhibits provirus transcription in HIV-infected T cells. EMBO J. 12: 4909-4921

38. Deen KC, McDougal JS, Inacker R, Folena-Wasserman G, Arthos J, Rosenberg J, Maddon PJ, Axel R and Sweet RW (1988) A soluble form of CD4 (T4) protein inhibits AIDS virus infection. Nature 331: 82-84

39. Bandres JC, Wang QF, O'Leary J, Baleaux F, Amara A, Hoxie JA, Zolla-Pazner $S$ and Gorny MK (1998) HIV envelope binds to CXCR4 independently of CD4, and binding can be enhanced by interaction with soluble CD4 or by HIV envelope deglycosylation. J. Virol. 72: 2500-2504

40. Mueller YM, De Rosa SC, Hutton JA, Witek J, Roederer M, Altman JD and Katsikis PD (2001) Increased CD95/Fas-induced apoptosis of HIV-specific CD8(+) T cells. Immunity 15: 871-882

41. Ostrowski MA, Justement SJ, Catanzaro A, Hallahan CA, Ehler LA, Mizell SB Kumar PN, Mican JA, Chun TW and Fauci AS (1998) Expression of chemokine receptors CXCR4 and CCR5 in HIV-1-infected and uninfected individuals. J. Immunol. 161: 3195-3201

42. Murphy PM (2001) Viral exploitation and subversion of the immune system through chemokine mimicry. Nat. Immunol. 2: 116-122

43. Olah Z, Lehel C, Anderson WB, Eiden MV and Wilson CA (1994) The cellular receptor for gibbon ape leukemia virus is a novel high affinity sodiumdependent phosphate transporter. J. Biol. Chem. 269: 25426-25431

44. van Zeijl M, Johann SV, Closs E, Cunningham J, Eddy R, Shows TB and O'Hara B (1994) A human amphotropic retrovirus receptor is a second member of the gibbon ape leukemia virus receptor family. Proc. Natl. Acad. Sci. USA 91: 1168-1172

45. Schaeffer E, Geleziunas R and Green WC (2001) HIV1 Nef functions at the level of virus entry by enhancing cytoplasmic delivery of virions. J. Virol. 75: 2993-3000

46. Zauli G, Gibellini D, Secchiero P, Dutartre H, Olive D, Capitani S and Collette $Y$ (1999) HIV1 Nef protein sensitizes CD4(+) T lymphoid cells to apoptosis via functional upregulation of the CD95/CD95 ligand pathway. Blood 93 1000-1010

47. Geleziunas R, Xu W, Takeda K, Ichijo H and Greene WC (2001) HIV-1 Nef inhibits ASK1-dependent death signalling providing a potential mechanism for protecting the infected host cell. Nature 410: 834-838

48. Wolf D, Witte V, Laffert B, Blume K, Stromer E, Trapp S, d'Aloja P, Schürmann A and Baur AS (2001) Nef-associated PAK and PI3-kinases stimulate Bad phosphorylation in an Akt-independent pathway. Implications for anti-apoptosis signaling in HIV-infected cells. Nat. Med. 7: 1217-1224

49. Ameisen JC (2001) Apoptosis subversion: HIV-Nef provides both armor and sword. Nat. Med. 7: 1181-1182

50. Monleon I, Martinez-Lorenzo MJ, Monteagudo L, Lasierra P, Taules M, Iturralde M, Pineiro A, Larrad L, Alava MA, Naval J and Anel A (2001) Differential secretion of Fas ligand- or APO2 ligand/TNF-related apoptosisinducing ligand-carrying microvesicles during activation-induced death of human T cells. J. Immunol. 187: 6736-6744

51. Martinez-Lorenzo MJ, Anel A, Gamen S, Monleon I, Lasierra P, Larrad L, Pineiro A, Alava MA and Naval J (1999) Activated human T cells release bioactive FasL and APO2 ligand in microvesicles. J. Immunol. 163: 1274-1281

52. Krammer P (2000) CD95's deadly mission in the immune system. Nature 407: 789-795

53. Andreola G, Rivoltini L, Castelli C, Huber V, Perego P, Deho P, Squarcina P, Accornero $P$, Lozupone F, Lugini L, Stringaro A, Molinari A, Arancia G, Gentile $M$, Parmiani $G$ and Fais $S$ (2002) Induction of lymphocyte apoptosis by tumor cell secretion of FasL-bearing microvesicles. J. Exp. Med. 195: 1303-1316

54. Schneider P, Holler N, Bodmer JL, Hahne M, Frei K, Fontana A and Tschopp J (1998) Conversion of membrane-bound Fas (CD95) ligand to its soluble form is associated with downregulation of its proapoptotic activity and loss of liver toxicity. J. Exp. Med. 187: 1205-1213

55. Huang DCS, Hahne M, Schroeter M, Frei K, Fontana A, Villunger A, Newton K, Tschopp J and Strasser A (1999) Activation of Fas by FasL induces apoptosis by a mechanism that cannot be blocked by Bcl-2 or Bcl-XL. Proc. Natl. Acad. Sci. USA 96: 14871-14876

56. Li CJ, Friedman DJ, Wang C, Metelev V and Pardee AB (1995) Induction of apoptosis in uninfected lymphocytes by HIV-1 Tat protein. Science 268: $429-431$

57. Bartz SR and Emerman M (1999) HIV-1 Tat induces apoptosis and increases sensitivity to apoptotic signals by upregulating FLICE/Caspase-8. J. Virol. 73: 1956-1963

58. Zauli G, Gibellini D, Caputo A, Bassini A, Negrini M, Monne M, Mazzoni M and Capitani S (1995) The HIV-1 Tat protein upregulates Bcl-2 gene expression in Jurkat T-cell lines and primary peripheral blood mononuclear cells. Blood. 86: 3823-3834

59. Chang HC, Samaniego F, Nair BC, Buonaguro L and Ensoli B (1997) HIV-1 Tat protein exits from cells via a leaderless secretory pathway and binds to extracellular matrix-associated heparan sulfate proteoglycans through its basic regions. AIDS 11: 1421-143

60. Lenardo MJ, Angleman SB, Bounkeua V, Dimas J, Duvall MG, Graubard MB, Hornung F, Selkirk MC, Speirs CK, Trageser C, Orenstein JO and Bolton DL (2002) Cytopathic killing of peripheral blood CD4+ T lymphocytes by HIV-1 appears necrotic rather than apoptotic and does not require env. J. Virol. 76: 5082-5093

61. Aupeix K, Hugel B, Martin T, Bischoff P, Lill H, Pasquali JL and Freyssinet JM (1997) The significance of shed membrane particles during programmed cell death in vitro, and in vivo, in HIV-1 infection. J. Clin. Invest. 99: 1546-1554

62. Hosaka N, Oyaizu N, Kaplan MH, Yagila H and Pahwa S (1998) Membrane and soluble forms of Fas (CD95) and FasL in peripheral blood mononuclear cells and in plasma from HIV-infected persons. J. Infect. Dis. 178: 1030-1039

63. O'Brien SJ and Moore JP (2000) The effect of genetic variation in chemokines and their receptors on HIV transmission and progression to AIDS. Immunol. Rev. 177: 99-111

64. Gervaix A, West D, Leoni LM, Richman DD, Wong-Staal F and Corbeil J (1997) A new reporter cell line to monitor HIV infection and drug susceptibility in vitro. Proc. Natl. Acad. Sci. USA 94: 4653-4658

65. Schwartz O, Maréchal V, Danos O and Heard JM (1995) HIV1 Nef increases the efficiency of reverse transcription in the infected cell. J. Virol. 69: 4053-4059

66. Landau N, Page KA and Littman DR (1991) Pseudotyping with human T-cell leukemia virus type I broadens the human immunodeficiency virus host range. J. Virol. 65: 162-169

67. Belloc F, Dumain $P$, Boisseau MR, Jalloustre C, Reiffers J, Bernard P and Lacombe $F$ (1994) A flow cytometric method using Hoechst 33342 and propidium iodide for simultaneous cell cycle analysis and apoptosis determination in unfixed cells. Cytometry 17: 59-65 